\title{
Manifestações patológicas em uma residência do programa habitacional em Santo Antônio de Jesus- BA.
}

\author{
A. Barboza ${ }^{1 *}$, L. Farias ${ }^{2}$, L. De Sousa ${ }^{3 *}$ \\ *Autor de Contato: lucarb08@gmail.com \\ ${ }^{1,3}$ Faculdade de Engenharia civil, Faculdade de Ciências e Empreendedorismo, FACEMP, \\ Santo Antônio de Jesus - Brasil \\ ${ }^{2}$ Doutoranda em Engenharia Civil, Universidade Federal do Rio de Janeiro, Rio de Janeiro - \\ Brasil
}

\section{RESUMO}

Com a crescente demanda por moradia no Brasil fez-se necessário a criação de programas habitacionais que concedem a pessoas de baixa renda moradia própria. Este estudo tem intuito de apresentar manifestações patológicas de uma residência do conjunto habitacional do programa Minha casa, Minha vida, denominado "Cidade Nova II", em Santo Antônio de Jesus e propor soluções. Foram notadas diferentes manifestações patológicas entre as quais o mofo e manchas de umidade foram as mais agravantes, sendo que afetam diretamente o bem-estar do morador. De acordo com o orçamento estimado para resolver os problemas patológicos, os custos chegaram a $24,08 \%$ do custo total da obra, sendo assim vultuosos em relação ao público-alvo (população de baixa renda) e à tipologia da edificação construída.

Palavras-chave: Manifestações patológicas; fase construtiva; construção civil. 


\begin{abstract}
With the growing demand for housing in Brazil, it has become necessary to create housing programs that provide low-income people with their own homes. The purpose of this study is to present the pathological manifestations of a residence in the housing complex of the Minha Casa, Minha Vida program, called "Cidade Nova II", in Santo Antônio de Jesus, and to propose solutions. Different pathological manifestations were noticed, among which mold and humidity stains were the most aggravating, directly affecting the dweller's well-being. According to the estimated budget for solving the pathological problems, the costs reached $24.08 \%$ of the total cost of the project, which is very high in relation to the target audience (low-income population) and the type of building constructed.
\end{abstract}

Keywords: Pathological manifestations; construction phase; civil construction.

\title{
RESUMEN
}

Con la creciente demanda de vivienda en Brasil, se ha hecho necesaria la creación de programas de vivienda que proporcionen a las personas de bajos ingresos su propia casa. Este estudio tiene como objetivo presentar las manifestaciones patológicas de una residencia del complejo habitacional del programa Minha casa, Minha vida, llamado "Cidade Nova II", en Santo Antônio de Jesus y proponer soluciones. Se observaron diferentes manifestaciones patológicas, entre las cuales las manchas de moho y humedad fueron las más agravantes, afectando directamente al bienestar del residente. De acuerdo con el presupuesto estimado para resolver los problemas patológicos, los costes alcanzaron el $24,08 \%$ del coste total de la obra, por lo que son elevados en relación con el público objetivo (población de bajos ingresos) y el tipo de edificio construido.

Palabras clave: Manifestaciones patológicas; fase constructiva; construcción civil.

\section{INTRODUÇÃO}


Com a ascensão do crescimento populacional no Brasil ficou cada vez mais evidente a escassez de moradias no país (Monteiro; Veras, 2017). Com o intuito de reverter essa situação, Olives (2017) relata que foi criado o Programa Minha Casa Minha Vida (PMCMV), um programa habitacional federal de iniciativa do governo brasileiro que tem como objetivo subsidiar a obtenção de casa ou apartamento próprio para pessoas com baixa renda, além de facilitar as condições de pagamento para que pessoas de classe média adquiram seu imóvel.

Dessa forma, foi proporcionada a população menos favorecida condições básicas e dignas de moradia, garantindo sua segurança, integridade e bem-estar (Monteiro; Veras, 2017). Na qual Olives (2017) apresenta que são imóveis considerados simples por sua estética mais comum e padronizada, mas contemplam seis cômodos distribuídos da seguinte forma: uma sala, dois quartos, uma cozinha integrada a área de serviço e um banheiro.

É importante ressaltar que toda edificação possui um ciclo de vida útil e muitas vezes, ao longo do tempo, por conta dos efeitos do ambiente, um ou mais elementos da construção podem sofrer uma perda progressiva do seu desempenho à medida que os materiais utilizados sofrem degradações ou alterações na sua composição (Bertolini, 2010).

A NBR 5674 (ABNT, 2012) dispõe que o uso e a manutenção adequada do imóvel se caracterizam como uma importante condição para a vida útil da construção. A norma técnica mencionada ressalta que tais manutenções devem ser feitas de forma periódica e preventiva, sendo que a negligência para essa ação compromete a segurança da edificação e seu bom desempenho, além de prejudicar a vida dos usuários. Edificações que não recebem manutenções podem se degradar antes do tempo previsto, assim como, fazer com que pequenas patologias evoluam, comprometendo a edificação e gerando custos elevados para sua recuperação (ABNT, 2012).

Porém, no caso dos imóveis do MCMV, desde o seu ato de entrega tem sido detectados diferentes tipos de anomalias, ou seja, patologias precoces que prejudicam o bom desempenho da estrutura como um todo (Olives, 2017). Fernández (1988) discute que a patologia faz parte da engenharia que estuda os mecanismos, os sintomas, as causas e as origens dos defeitos das obras.

Fernández (1998) reforça ainda que esse estudo a depender do grau de desenvolvimento da patologia pode ser feito de forma visual ou com a utilização de ferramentas tecnológicas. Corroborado por Ripper et al. (1998) e Helene (2002) que analisam que a patologia nas construções é semelhante à Ciência Médica, já que estuda os sintomas, formas de manifestação, origens e causas das doenças ou falhas que ocorrem nas edificações.

Dentre essas manifestações, podem ser citadas algumas mais comuns como: fissuras, infiltrações e mofo. Sobre a fissuração pode-se analisar vários fatores geradores, como a retração, variação de temperatura e a agressividade do meio ambiente, analisando o sentido e ângulo em que o dano se apresenta na superfície da edificação, denota o tipo de sobrecarga de tração ou compressão da estrutura, auxiliando no entendimento da causa e efeito destas manifestações patológicas (Vitório, 2003).

Já em relação às infiltrações, Côrrea (2010) caracteriza como patologias das alvenarias relacionadas com a presença de água nos blocos que a compõem, podendo ocasionar manchas de umidade, bolor, fungos, algas, eflorescências, descolamento, desagregação e mudança de coloração. Estas manifestações podem ser geradas devido à absorção capilar superficial de água por condensação.

Para evitar problemas com umidade sugere-se que durante a fase de projeto se analise os vários aspectos causadores do problema com intuito e de minimizar as infiltrações. Dentre esses aspectos pode-se citar a orientação das fachadas em relação aos ventos predominantes, detalhes 
arquitetônicos e técnicos como rufos, platibandas, beirais, tipo de cobertura e a intensidade e a duração das precipitações na região (Côrrea, 2010).

Gnipper e Mikaldo Jr. (2007) apresenta que muitas patologias manifestadas por esses fenômenos incidem repetitivamente nos edifícios o que revela falhas sistêmicas na fase de projeto desses sistemas prediais. Do Carmo (2003) ressalta que a prevenção é a melhor estratégia para que a construção apresente desempenho satisfatório durante sua vida útil.

Portanto, a caracterização da natureza das patologias e inconformidades mais frequentes nesse universo pode contribuir para uma ação preventiva durante a etapa de concepção do projeto de novas edificações, visando diminuir a incidência de tais problemas a níveis satisfatórios aos usuários.

\section{METODOLOGIA}

Foi realizada uma pesquisa exploratória sobre as manifestações patológicas em construções do programa Minha Casa, Minha Vida (MCMV), descrevendo os fatos observados e características das edificações, registrando e analisando-os.

Inicialmente, o estudo utilizou de uma pesquisa bibliográfica que levou a uma discussão teóricoconceitual e ao desenvolvimento da fundamentação teórica. Foram pesquisados e analisados materiais científicos a citar: livros bibliográficos, artigos científicos e monografias. Na busca foram utilizadas as palavras-chave: manifestações patológicas residência; programa habitacional; patologias; minha casa minha vida.

Em paralelo, foi realizado o estudo de caso com base em uma residência do programa habitacional MCMV. A seleção da residência foi feita por conveniência devido às características práticas do estudo e, principalmente, pelo acesso as informações necessárias. A partir da residência, a escolha para desenvolvimento do estudo são as manifestações patológicas apresentadas na construção. A amostragem por conveniência, de acordo com Hair (2005, p. 247), "envolve a seleção de elementos da amostra que estejam mais disponíveis para tomar parte no estudo e que podem oferecer as informações necessárias”.

\subsection{Caracterização do emprendiendo e da edificação analisada}

O município de Santo Antônio de Jesus, na Bahia, possui 102.380 habitantes (IBGE, 2020), uma densidade demográfica de $348,14 \mathrm{hab} . / \mathrm{km}^{2}$ e índice de desenvolvimento humano municipal de 0,700, avaliado em 2010 (IBGE, 2020). Esta cidade possui um ambiente de baixa agressividade ambiental e programas habitacionais implementados.

A cidade conta com dois conjuntos habitacionais de incentivo Federal para famílias com baixa renda. O primeiro a ser construído foi o "Zilda Arns', localizado na Rua do Cajueiro, bairro Cajueiro, inaugurado em 2013. O segundo a ser construído foi o "Cidade Nova II", localizado na Rua Açougue Velho, bairro Santa Terezinha, inaugurado em agosto de 2015. Os conjuntos habitacionais detêm de 500 e 784 moradias, respectivamente, segundo manual do proprietário emitido pelas construtoras responsáveis.

A área de estudo é caracterizada como uma residência térrea, fruto da iniciativa Federal e com parceria entre o Banco do Brasil e a uma construtora, localizado na "Cidade Nova II", seguindo todas as exigências de projetos. Este empreendimento foi finalizado há 5 anos, entregues a população em agosto de 2015, instalada em um terreno com área de 45,88 $\mathrm{m}^{2}$, contendo de 43,22 $\mathrm{m}^{2}$ de área construída, dispostos em seis cômodos: uma sala, dois quartos, uma cozinha integrada a área de serviço e um banheiro. 
A edificação é localizada à rua açougue velho, $n^{\circ} 01$, rua 1 , quadra 16 , bairro Santa Terezinha Santo Antônio de Jesus/BA, conforme demonstrado nas imagens a seguir (Figura 1 e Figura 2, respectivamente).

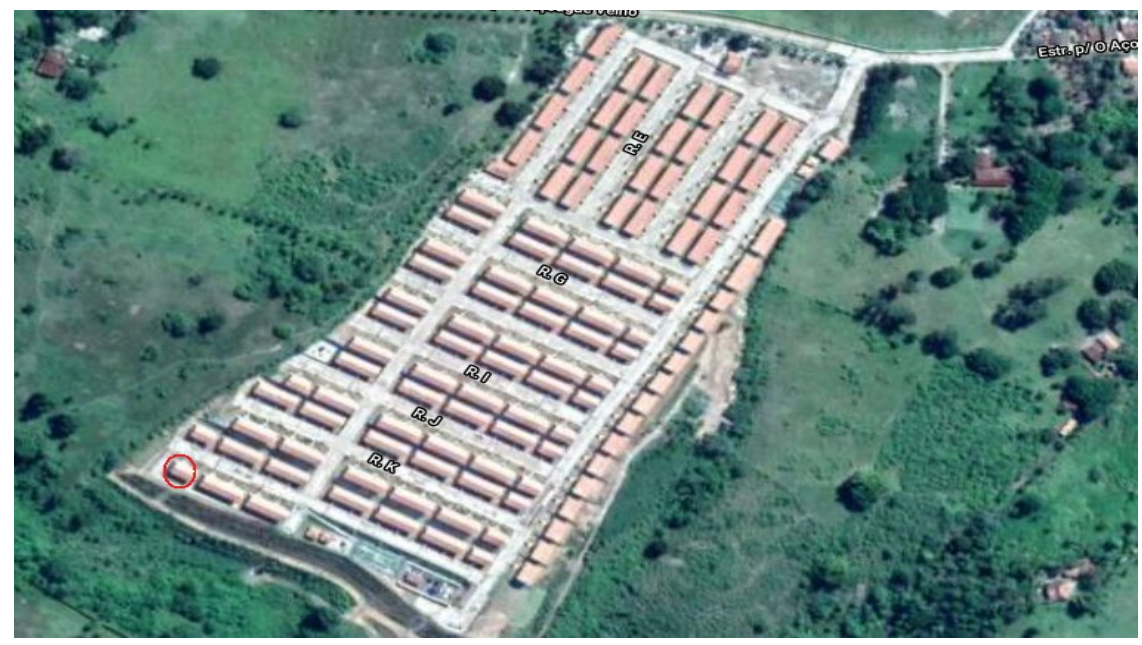

Figura 1. Caracterização da área de estudo e seleção da edificação estudada. Fonte: Google Maps.

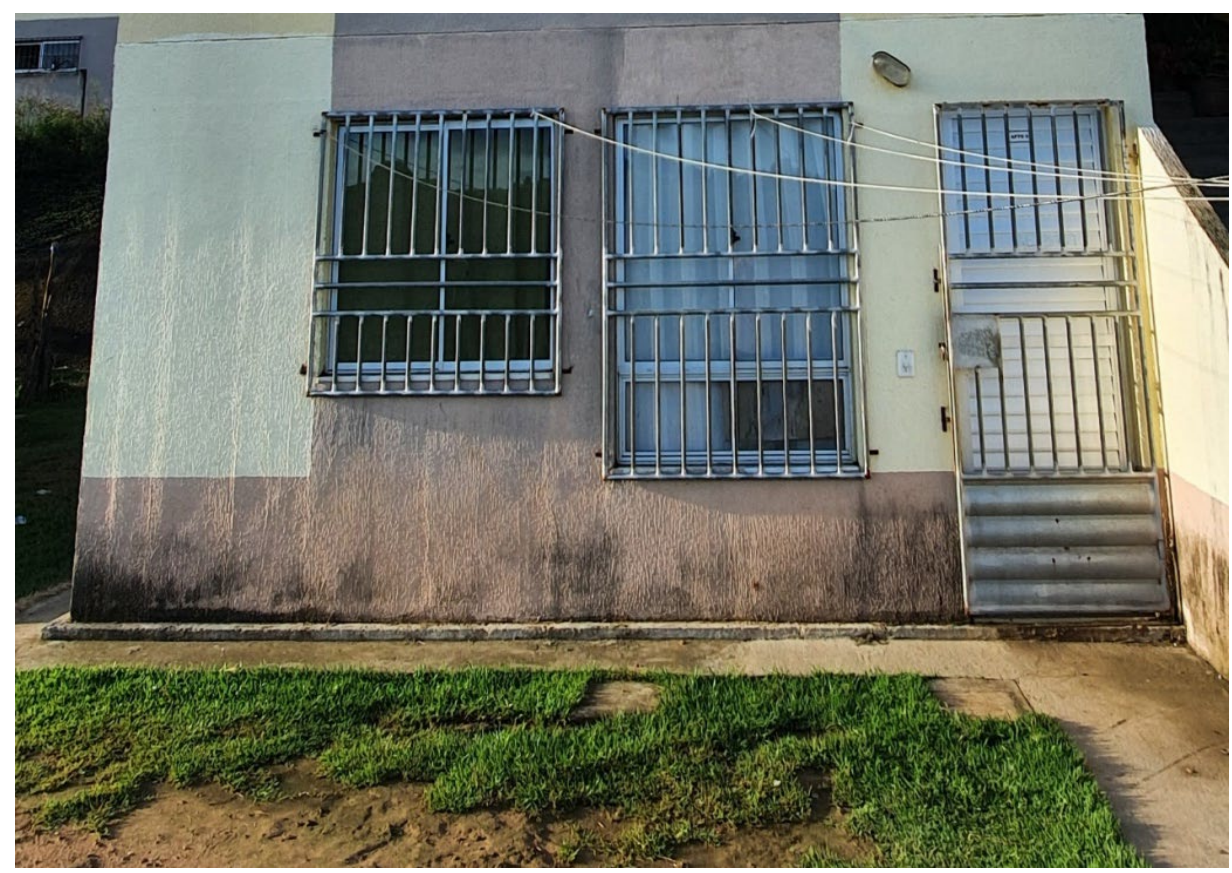

Figura 2. Fachada da residência estudada

Os itens que foram analisados ao longo das observações in loco foram presença de mofo, fissuras, umidade ascendente e infiltrações.

Sobre os passos que foram realizados na coleta de dados, cita-se o primeiro contato com o responsável pela residência escolhida para o estudo, explicando o propósito da investigação para que posteriormente seja feito o compartilhamento dos dados e de possíveis soluções. Foi realizada 
uma pesquisa documental e exames complementares (roteiro de observação) consistindo na avaliação das manifestações encontradas na residência e suas possíveis causas, obtida através de vistorias e apresentado por meio de relatórios fotográficos.

$\mathrm{Na}$ análise dos dados foi utilizada a técnica de análise de conteúdo, onde as respostas qualitativas dos roteiros de observação foram analisadas e interpretadas pelo pesquisador, buscando convergir itens e elementos similares ou próximos. As anotações do pesquisador, diante das leituras realizadas durante o levantamento bibliográfico, também foram comparadas com os resultados, assim como as fotografias.

As informações coletadas e os registros fotográficos foram analisados minuciosamente, valendose de autores pré-selecionados e intimamente relacionados ao tema com a finalidade explicitar causas e soluções para as adversidades encontradas.

\section{RESULTADOS}

\subsection{Análise das manifestações patológicas}

Na Figura 3 foi identificada a manifestação patológica 01, na qual foram notadas bolhas, manchas de umidade ascendente por capilaridade e saponificação. Esta patologia foi analisada na Tabela 1 .

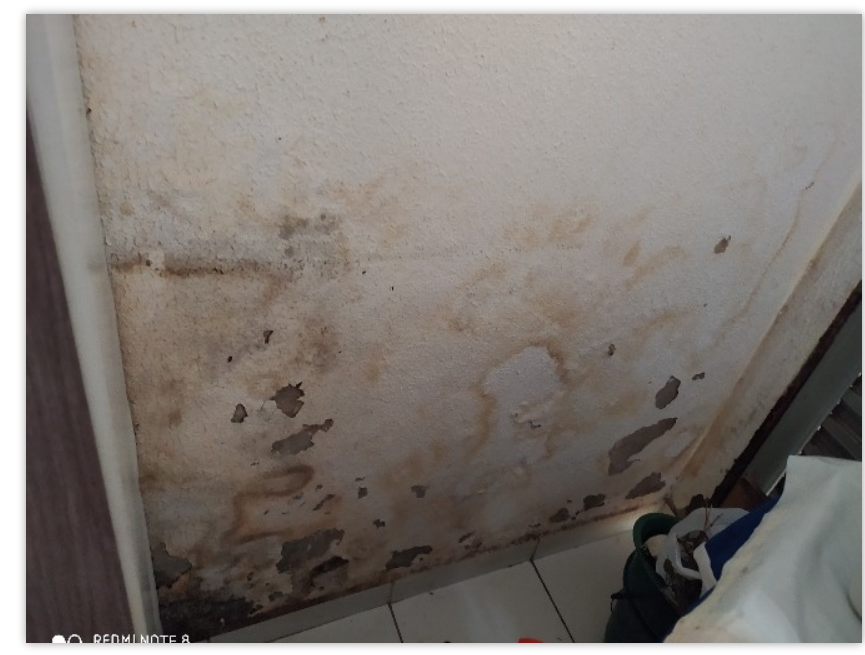

Figura 3- Manifestação patológica 01.

Tabela 1. Descrição da manifestação patológica 01, possível causa e sugestão terapêutica.

Descrição por inspeção visual: 
Manifestação encontrada na parede externa a cozinha e interna ao banheiro

Manifestações detectadas / Diagnóstico:

Bolhas, manchas de umidade ascendente por capilaridade e saponificação

Possível causa:

Umidade na superfície, tinta não apropriada ao ambiente de uso, ou utilizada sem observaro período de cura do reboco ou revestimento.

Sugestão de terapêutica adequada:

Sanar a fonte de umidade incidente na alvenaria. Remover todo o reboco até a alvenaria, sobre as superfícies em alvenaria promover um chapisco no traço 3:1 (areia/cimento), aditivado adesivo impermeabilizante, nivelar e aguarda a cura. Após a cura, aplicar um impermeabilizante cimentício de base acrílica com consumo mínimo de $3 \mathrm{~kg} / \mathrm{m}^{2}$. Após a última demão do impermeabilizante, aplicar um chapisco novamente, aguardar a cura e aplicar um novo reboco e finalizar com o revestimento.

Quando se trata de saponificação, Polito (2006) relata que esta reação ocorre devido ao material cimentício possuir alcalinidade ( $\mathrm{pH}$ alcalino em função do teor de cálcio), friabilidade (facilidade de desagregar ao sofrer fricção) e aptidão a absorver e reter umidade. Segundo o qual os álcalis são as raízes de parte vultuosa dos problemas entre o substrato e a pintura.

Para Roque (2006, p. 46), "a umidade ascendente existente nas alvenarias é gerada na absorção da água presente no solo através de elementos construtivos, tais como; fundações, vigas baldrame e lajes térreas (radiers)".

Na Figura 4 pode-se identificar a presença de mofo nas paredes (manifestação patológica 02), cuja análise se encontra na Tabela 2.

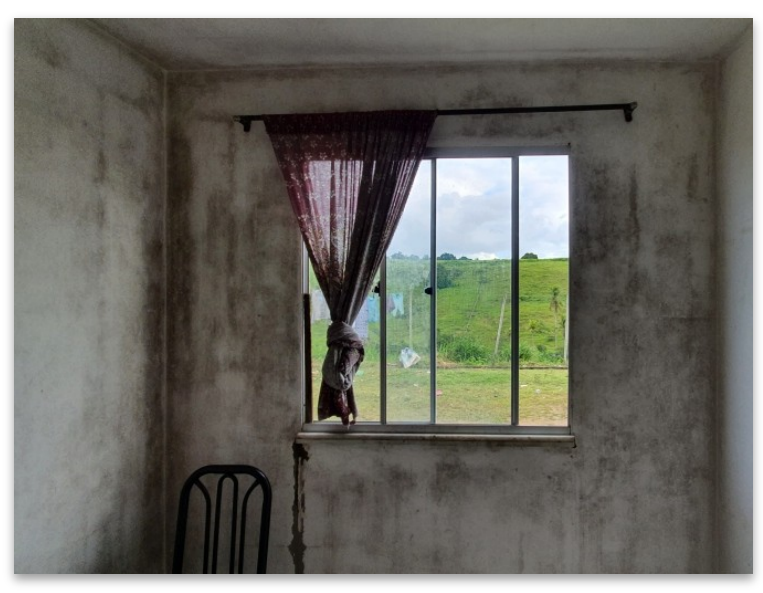

Figura 4. Manifestação patológica 02.

Tabela 2. Descrição da manifestação patológica 02, possível causa e sugestão terapêutica. 
Descrição por inspeção visual:

Manifestação encontrada na parede interna do quarto.

Manifestações detectadas / Diagnóstico:

Manchas de mofo na superfície da parede, principalmente nas junções das paredes e teto.

Possível causa:

Umidade superficial, infiltrações prevenientes do exterior da parede, falta de ventilação iluminação eficazes.

Sugestão de terapêutica adequada:

Sanar as causas que possam ter contribuído para o desenvolvimento da patologia. Impermeabilizar $\mathrm{a}$ área externa à parede com a manta liquida impermeabilizante, em no mínimo duas demãos, não aplicar sobre base quente.

Remover todo o reboco até a alvenaria, sobre as superfícies em alvenaria promover um reboco no traço 1:2:6 (cimento/cal/areia), aditivado adesivo impermeabilizante, nivelar e aguardar a cura.

O mofo é uma classe da patologia que provoca alterações na superfície da parede, requisitando, na maior parte dos casos, a restauração ou inclusive a necessidade de substituição de todo revestimento, causando elevados custos de recuperação (Souza, 2008). Para Cechinel et al., (2011), o mofo é causado pela umidade proveniente da infiltração, visto que os fungos necessitam de água para se reproduzirem. Na alvenaria, nota-se a manifestação do mofo quando se evidencia o surgimento de manchas e escurecimento da superfície.

Na Figura 5 foi identificada a manifestação patológica 03 que se trata de desplacamento do piso cerâmico, esta patologia foi analisada na Tabela 3.

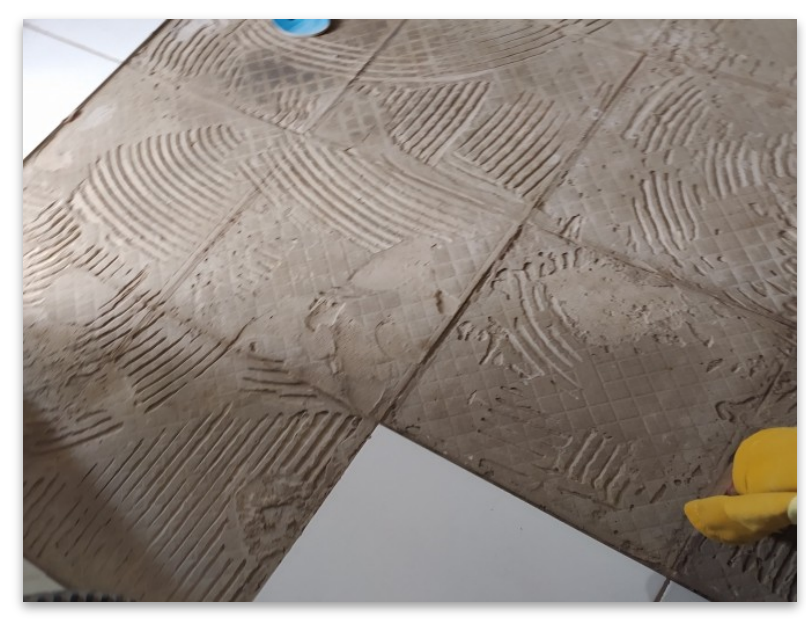

Figura 5. Manifestação patológica 03.

Tabela 3. Descrição da manifestação patológica 03, possível causa e sugestão terapêutica.

Descrição por inspeção visual: 
Manifestação encontrada no revestimento do chão da sala.

Manifestações detectadas / Diagnóstico:

Desplacamento de piso cerâmico e perda de aderência.

Possível causa:

Assentamento incorreto, dosagem incorreta da argamassa de assentamento, movimentação do substrato (solo), falta de juntas de dilatação e movimentação no revestimento.

Sugestão de terapêutica adequada:

Sanar as causas que possam ter contribuído para o desenvolvimento da patologia. Em seguida remover todo o revestimento e limpar bem a superfície com escova de fio de aço. Feito isso devese verificar o estado do contrapiso, observando se o mesmo está se desagregando e se está apto ao novo revestimento, em caso positivo fazer o reassentamento do piso, atentando-se ao procedimento correto do mesmo, utilizar argamassa própria ao tipo do piso e executar as juntas de dilatação especificadas no manual do fabricante do revestimento.

De acordo com Campante e Sabbatini (2001, p. 9-10), "grande parte das ocorrências de patologias em revestimento cerâmico pode ser conferida à falta de compreensão e conhecimento das interações entre seus diferentes componentes". Tal falta de compreensão está relacionada às deficiências no conhecimento técnico de todo o processo construtivo, tais quais; mão de obra desqualificada, falta de assistência técnica por parte dos fabricantes e a falta de cumprimento das normas vigentes e das orientações do manual do fabricante anexo aos materiais.

A perda de aderência sintetiza um processo causado por falhas e rupturas na área de interação entre as camadas do revestimento cerâmico, ou meio a base e o substrato (estrutura, contrapiso etc.). Essa perda de aderência manifesta-se a modo que as tensões que surjam ultrapassem a capacidade de aderência das ligações (Barros et al., 1997).

Na Figura 6 foi identificada a manifestação patológica 04, correspondendo a manchas proveniente de fungos e microrganismo sendo analisada na Tabela 4.

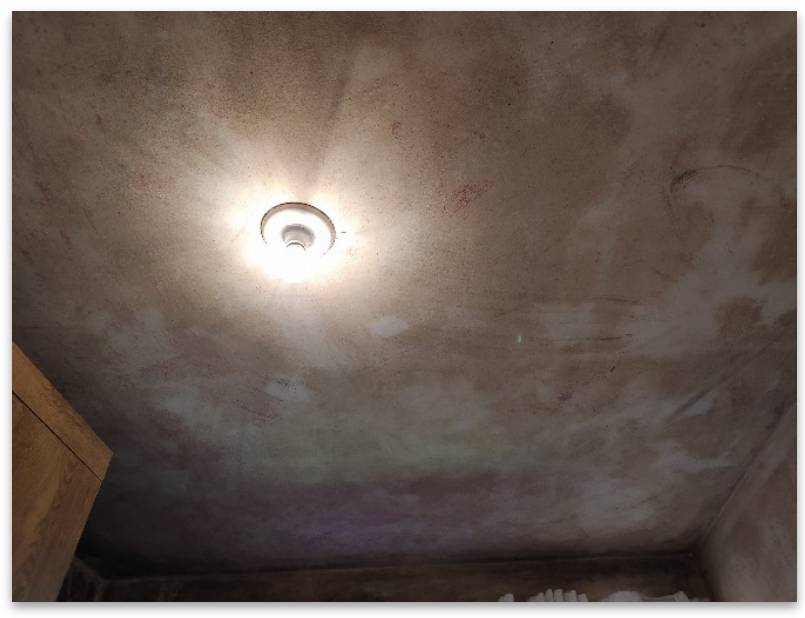

Figura 6. Manifestação patológica 04.

Tabela 4. Descrição da manifestação patológica 04, possível causa e sugestão terapêutica.

Descrição por inspeção visual: 
Manifestação encontrada no teto do quarto.

Manifestações detectadas / Diagnóstico:

Manchas provenientes de Mofo e microrganismos.

Possível causa:

Umidade do ar ambiente, falta de ventilação efetiva, falta de incidência de calor e luz natural.

Sugestão de terapêutica adequada:

Sanar as causas que possam ter contribuído para o desenvolvimento da patologia. Em seguida remover todo o revestimento e limpar bem a superfície. Feito isto deve-se realizar a pintura com a tinta acrílica bactericida, esta irá inibir a umidade e a proliferação de fungos e bactérias causadoras do mofo.

Gertis, Erhorn e Reiss (1999) e Sedlbauer (2001) relatam que as condições ideais para o crescimento do mofo são: umidade relativa do ar acima de $80 \%$ com temperaturas superficiais superiores a $20^{\circ} \mathrm{C}$ e ventilação precária, sendo estas as condições mínimas para a proliferação de várias espécies de bolor de modo geral (sem diferenciar as espécies).

"Pesquisas sobre a nutrição de fungos em materiais de construção apontam que o teor de sais e a umidade presentes na argamassa podem influenciar no crescimento de fungos" (Yu; Kim, 2010, p. 2).

Na Figura 7 foi identificada a manifestação patológica 05 que corresponde a manchas provenientes de bolor e microrganismo. Foi feito uma análise na Tabela 5.

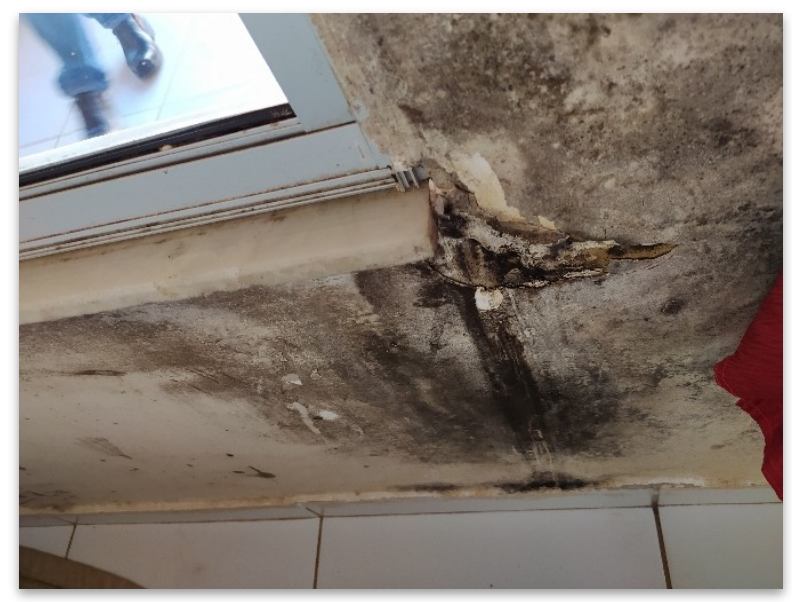

Figura 7. Manifestação patológica 05.

Tabela 5. Descrição da manifestação patológica 05, possível causa e sugestão terapêutica.

Descrição por inspeção visual: 
Manifestação encontrada na parede da fachada da casa.

Manifestações detectadas / Diagnóstico:

Manchas provenientes de bolor e microrganismos.

Possível causa:

Umidade do ar ambiente, falta de ventilação efetiva, má execução da soleira de granito e da pingadeira.

Sugestão de terapêutica adequada:

Sanar as causas que possam ter contribuído para o desenvolvimento da patologia. Após isto remover todo o revestimento e limpar bem a superfície. Em seguida deve-se realizar a pintura com a tinta acrílica bactericida, esta irá inibir a umidade e a proliferação de fungos e bactérias. Executar

a colocação correta da soleira e da pingadeira.

Os bolores instituem o crescimento de fungos sobre os substratos, de acordo com Shirakawa (1995). O mesmo autor reitera que a formação de bolor possui suas principais causas extrínsecas ao material, e com relação direta ao aumento de umidade tanto interna quanto externa da edificação. A exemplo, a umidade ascendente por capilaridade, infiltrações, vazamentos, alta umidade relativa do ar e condensação de vapores em ambientes confinados.

Observa-se, que o material individualmente não é causador de bolor ou mofo, pois mesmo que ele possua em sua maioria as características necessárias para o crescimento dos fungos, o bolor não aparecerá se a umidade não for suficiente, afirma Shirakawa (1995).

Na Figura 8 foi identificada a manifestação patológica 06, identificada como rachadura na estrutura. A análise desta manifestação é apresentada na Tabela 6.

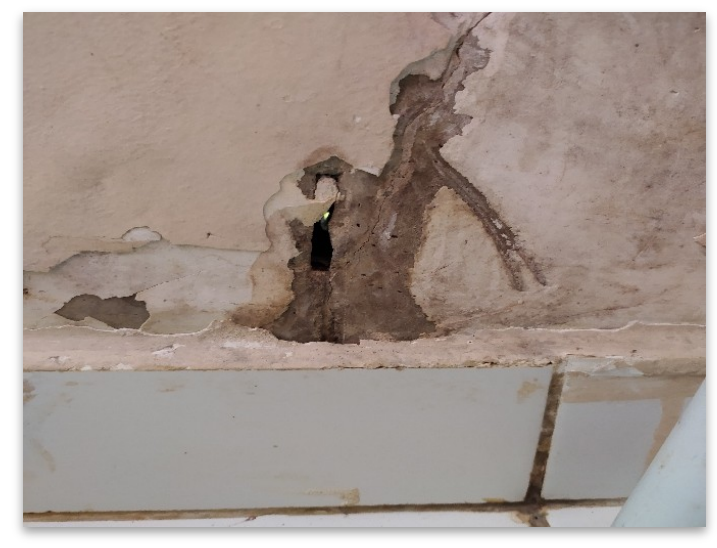

Figura 8. Manifestação patológica 06.

Tabela 6. Descrição da manifestação patológica 05, possível causa e sugestão terapêutica.

Descrição por inspeção visual: 
Manifestação encontrada próximo ao rodapé da casa.

Manifestações detectadas / Diagnóstico:

Rachadura na estrutura / ninho de concretagem

Possível causa:

Falta de vibração do concreto, lançamento do concreto em altura acima de $2 \mathrm{~m}$.

Sugestão de terapêutica adequada:

Sanar as causas que possam ter contribuído para o desenvolvimento da patologia. Em seguida limpar toda a superfície utilizando escova de aço, remover pedaços que venham a ser segregados, feito isso confeccionar uma forma e encher os espaços vazios com concreto ou argamassa de alta resistência, obedecendo as recomendações do manual do fabricante e vibrar ou apiloar a massa

para obter o adensamento ideal.

Ninhos são vazios nas peças de concreto provenientes de má vibração, falha no transporte do concreto e erros na concretagem que impedem que a argamassa preencha todos os locais dentro da forma, deixando espaços vazios entre os agregados. Os ninhos de concretagem reduzem a seção transversal da peça e facilitam a entrada de agentes agressivos, estes por sinal agridem a estrutura reduzindo sua resistência gradativamente (Sena, et al., 2020; Ripper; Souza, 1998).

A NBR 14931 (ABNT, 2004) prevê que imediatamente após o lançamento o concreto deve ser vibrado de forma contínua e energética, com equipamento adequado à sua consistência. $\mathrm{O}$ adensamento deve ser acurado, a fim de que o concreto ocupe toda a forma. Durante o processo de adensamento deve-se cumprir os cuidados necessários para que não se formem ninhos ou ocorra a segregação dos materiais.

\subsection{Análise de custos para realização das terapéuticas necessárias}

Preços para recuperação manifestações patológicas verificadas e foram elaborados considerandose as dimensões da construção e valores referente a tabela SINAPI-BA (dezembro de 2020). Na Figura 9, encontra-se o gráfico com os custos associado de cada etapa de correção das patologias.

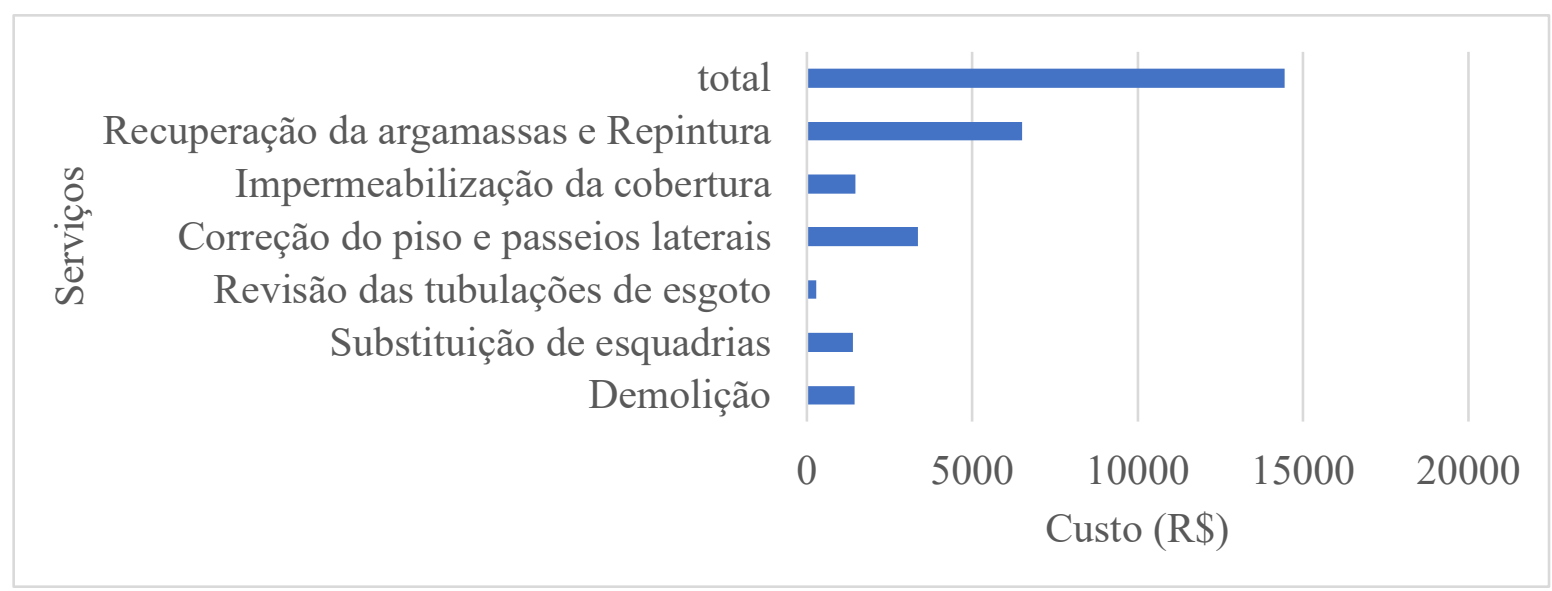

Figura 9. Custos dos procedimentos de correção das manifestações patológicas.

O valor estimado para reparação dos danos oriundos de manifestações patológicas na residência estudada é de $\mathrm{R} \$ 14.446,27$ (quatorze mil reais quatrocentos e quarenta e seis reais e vinte e sete centavos). A edificação custou $\mathrm{R} \$ 60.000,00$ (sessenta mil reais) desta quantia $\mathrm{R} \$ 57.000$ 
(cinquenta e sete mil reais) foram subsidiados pelo Governo federal, restando R $\$ 3.000$ (três mil reais) devidos pelo morador, distribuídos em 120 parcelas de $\mathrm{R} \$ 25,00$ (vinte e cinco reais), vide contrato particular de compra e venda. Podemos observar, pela análise da Figura 9, que os custos para a restauração das anomalias encontradas na residência ficaram vultuosos, alcançando no total de $24,08 \%$ do custo total da construção, sendo que a recuperação de argamassa e repintura foi significativo $(10,84 \%)$.

Salienta-se que a edificação foi construída para atender a pessoas de baixa renda, e estes, por sinal, podem não contemplar desta quantia, destaca-se também que, tais anomalias poderiam ser previamente evitadas na etapa de projeto e execução, e dessa forma eximir-se-ia as famílias destes transtornos físicos e psicológicos e financeiros.

\section{CONCLUSÕES}

Para o estudo do caso de uma residência do programa habitacional, infere-se que a maioria das manifestações encontradas foram oriundas possivelmente de erros ocorridos na execução do projeto, assim como o não cumprimento dos processos construtivos e normas técnicas necessários ao bom desempenho da edificação.

O controle e prevenção de manifestações patológicas nas construções detém de singular importância, principalmente em conjuntos habitacionais, pois estes são cada vez mais necessários e representam uma conquista, um marco para a população de baixa renda no Brasil.

Faz-se necessário portanto que seja dada a devida importância para todas as etapas dos processos construtivos de uma edificação, assim como às normas técnicas vigentes, evitando-se assim danos futuros. É fundamental também que estes preceitos sejam incorporados as condutas dos profissionais da área, para que seja dada a devida atenção e responsabilidade para com suas obras e consequentemente com os futuros usuários da edificação.

\section{AGRADECIMENTOS}

Os autores agradecem a Faculdade de Ciências e Empreendedorismo pelo apoio e incentivo fornecido ao desenvolvimento do presente trabalho.

\section{REFERÊNCIAS}

Associação Brasileira De Normas Técnicas - ABNT. NBR 5674: Manutenção de Edificações: Procedimentos. Rio de Janeiro, 2012.

Barros, M. M. B.; Taniguti, E. K.; Ruiz, L. B.; Sabbatini, F. H. Tecnologia construtiva racionalizada para a produção de revestimentos cerâmicos verticais. Notas de aula. São Paulo: USP, 1997.

Bertolini, L. Materiais de Construção: patologia, reabilitação, prevenção; tradução Leda Maria Marques Dias Beck. São Paulo: Oficina de Textos, 2010.

Campante, E. F.; Sabbatini, F. H. Metodologia de diagnóstico, recuperação e prevenção de manifestações patológicas em revestimentos cerâmicos de fachada. São Paulo: USP, 2001. Boletim técnico n. 301. 
Cechinel, M. B. Vieira, F. L., Mantelli, P., Tonel, S. Infiltração em alvenaria- Estudo de caso em edifico na grande Florianópolis. Instituto Federal de Educação, Ciência e tecnologia de Santa Catarina-IF-SC, 2011.

Do Carmo, P. O. Patologia das construções. Santa Maria, Programa de atualização profissional - CREA - RS, 2003.

Fernández C., M. Patologia e terapia do concreto armado. Tradução de M. Celeste Marcondes, Carlos Wagner Fernandes dos Santos, Beatriz Cannabrava. São Paulo: Pini, 1988.

Gertis, K.; Erhorn, H.; Reiss, J. Klimawirkungen und Schimmelpilzbildung bei sanierten Gebäuden (Climate effects and 159 mold formation in renovated buildings). Building Physics. Anais...Berlin: 1999

Gnipper, S.; Mikaldo Jr. J. Patologias frequentes em sistemas prediais hidráulicosanitários e de gás combustível decorrentes de falhas no processo de produção do projeto. Curitiba, 2007.

Hair, Jr., Joseph F. Fundamentos de Métodos de Pesquisa. Porto Alegre: Bookman, 2005. 471 p.

Helene, P. R. L. Manual para reparo, reforço e proteção de estruturas de concreto. São Paulo, Pini, 2002.

Instituto Brasileiro de Geografia e Estatística - IBGE. Disponível na internet: https://www.ibge.gov.br/cidades-e-estados/ba/santo-antonio-de-jesus.html. Acesso em: 10 de novembro de 2020.

Monteiro, A. Roseno; Veras, A. T. R. A QUESTÃO HABITACIONAL NO BRASIL. Mercator (Fortaleza), Fortaleza, v. 16, e16015, 2017.

Olives, S. J. C. Desafios e Fragilidades do Trabalho Social no Programa Minha Casa Minha Vida na Região Metropolitana de Natal. Dissertação de Mestrado em Estudos Urbanos e Regionais. Universidade Federal do Rio Grande do Norte - Centro de Ciências Humanas, Letras e Artes. Natal, 2017.

Polito, G. Principais Sistemas de Pinturas e suas Patologias. Universidade Federal de Minas Gerais. Minas Gerais, 2006.

Ripper, T.; Souza, V. C. M. Patologia, Recuperação e Reforço de Estruturas de Concreto. Editora Pini, São Paulo, 1998.

Roque, J. A. O desempenho quanto à durabilidade de alvenarias de blocos cerâmicos de vedação com função auto portante: o caso da Habitação de Interesse Social. 2009. Tese de Doutorado, Universidade de Campinas, São Paulo. 
Sena, G. O., Nascimento, M.L.M., Neto, A. C. N. N., Lima, N. M. Patologias das construções. Editora 2B, Salvador-BA, 2020.

Shirakawa, M. A., Monteiro, M., Selmo, S.D.S., Cincotto, M.A. Identificação de fungos em revestimentos de argamassa com bolor evidente. I Simpósio brasileiro de tecnologia das argamassas. Goiânia-GO, 1995.

Souza, F. M. Patologias ocasionadas pela umidade nas edificações. Trabalho de Conclusão de Curso de Engenharia Civil. Escola de Engenharia da UFMG. Belo Horizonte, 2008

Vitório, A. Fundamentos da patologia das estruturas nas perícias de engenharia. Instituto Pernambucano de Avaliação e Perícias de Engenharia. Recife, 2003.

Yu, C. W. F.; Kim, J. T. Building pathology, investigation of sick buildings-VOC emissions. Indoor and Built Environment, v. 19, n. 1, p. 30-39, 2010. 